\title{
Kinematic analysis of maximum velocity phase in 100m hurdles: A case study
}

\section{Dr. Essam Fathy Ghareb}

Track and Field Training Department, Faculty of Sport Education for men, Alexandria University

\section{Dr. Moamen Mohamed Abd El gawad}

Track and Field Training Department, Faculty of Sport Education for men, Alexandria University

\section{Introduction:}

Understanding human movement is one of the most important tasks in the field of scientific Research. The human body consists of manysegments which move due to muscles contraction, so the biomechanical analysis is one of the most important tools that could help us to understand in details the human motion.

In track and field events, biomechanical analysis is an important tool to evaluate athletic performance, and provide coaches, athletes and researchers with useful data which can help them to develop and achieve a high level of performance.

Hurdles events, especially the high hurdles, are among the most demanding events of track and field. The athlete must possess both (speed of a sprinter combined with a high level of technical ability to clear ten hurdles with a minimum loss of horizontal velocity.[2]

Also, it requires a high potential of motor skill inaddition to a high level of technical preparation Which require a specific skill preparation during the entire training process. 


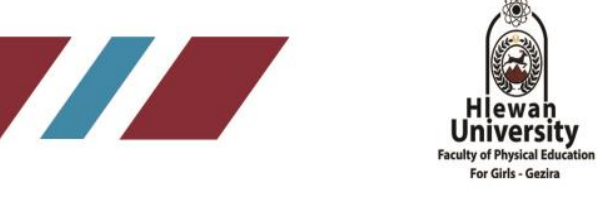

Success in hurdles events depends on many factors such as the appropriate morphological characteristics (body height, leg length) and specific motor abilities such as power, speed and speed endurance.[1,12]

As any sprint event, the main goal of the hurdle events is to cover the race distance as fast as possible while clearing ten hurdles. From biomechanical view it consists of three main phases start and acceleration phase, maximum velocity phase and deceleration phase. However, hurdles events has a unique structure that it consists of combination between sprinting and hurdle clearance (the continues transition from cyclic movement to acyclic movement)[1,4]

From technical view both men's 110 meters hurdles and women's 100 meters hurdles events include specific characteristics phases determined by the athlete's position to the hurdle (Brüggemann,1990). From this point of view, the 100m hurdles event consists of the following phases Approach run phase: the first eight steps before the first hurdle. Hurdle unit phase:

Preparatory step, Hurdle step (take-off distance and landing distance), Landing step and Recovery step. Run-in phase: the strides between the last hurdle and the finish line.[3,6]

Success in the women's 100m hurdles depends on the optimal combination and continuous alternation between sprinting (cyclical movement) and hurdle clearance (acyclic movements with a minimum loss of horizontal velocity.[8].Although previous studies suggested 


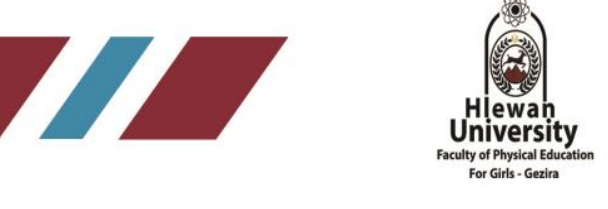

that female's $100 \mathrm{~m}$ hurdles has less technical demands than men's 110 meters Hurdles due to the relatively low barrier height compared to men's 110 meters hurdles,[3,4,6,10] fast hurdle step is a key role in success in women's 100 meters hurdles.

Hurdle clearance is considered to be one of the most important tasks of both women and men's hurdles hurdle race structure, it characterized by many factors such as minimal loss of velocity, a low flight path of the centre of gravity as flat as possible effective transitions from sprinting to hurdle step and the fast transition from hurdle step to sprinting [8] By analysis hurdle step time for each hurdle $0.30-0.33 \mathrm{sec}[11]$ for an average woman hurdler (13.50 sec in 100 meter hurdles) it can be concluded that hurdle clearance time has a proximally a percentage of $4-4.5 \%$ of total race time.

Considering the velocity curve of $100 \mathrm{~m}$ hurdles we found that horizontal velocity increases from the start to the 2 nd and 3rd hurdle ( acceleration phase ) and from the 3rd lo the 6th hurdle( maximum velocity phase ). Then, velocity is maintained for a while and decreases from the 6 hurdle to the finish (deceleration phase). $[5,7]$

Many previous studies have been focused onkinematic analysis of hurdle step of elite men hurdlers $[1,4,8,12,9,14,13]$ and women $100 \mathrm{~m}$ hurdles $[3,4,7,8,11,15]$,or using force plat form to examine ground reaction forces during men's 110 meters hurdles[2,13] The purpose of the presented study is to determine the specific kinematical changes related to hurdle clearance and comparing it with the specific kinematical variables in each phase in the national 


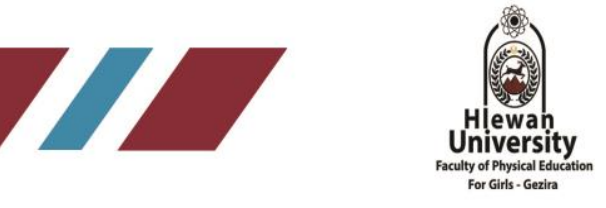

championwith elite athletes.

\section{Methods:}

\section{Subject:}

One elite female 100 meter hurdler $L A$ (height $1.65 \mathrm{~m}$, weight $63.5 \mathrm{~kg}$, PB $13.64 \mathrm{sec}$ ) who came 16th during the world junior athletics championship in Poland 2016 and Egyptian record holder was recorded in a training session during the preparation to the national championship.

\section{Data collection:}

During the training session, and after an appropriate warm up, the subject was asked to run a $60 \mathrm{~m}$ meter hurdles with maximum effort from block start. Two (2) video cameras $50 \mathrm{f} / \mathrm{s}$ (model Panasonic HC-V10 ) were used to collectkinematic data of hurdle step, the cameras were positioned perpendicular to the $4^{\text {th }}$ and $5^{\text {th }}$ hurdles respectively with a field of view $8 \mathrm{~m}$ ( to cover hurdle step and both take off and landing steps) a scale $1 \mathrm{~m} \times 1 \mathrm{~m} \times 1 \mathrm{~m}$ was positions in hurdle marks before running to scale kinematic data. The subject was prepared to the testing procedures by attaching 4 body marks on the lead leg (left leg) on the following anatomical

points: Hip joint (the greater trochanter), knee joint (the savage), ankle (lateral malleolus) and forefoot. The kinematic analysis was performed using DARTFISH team pro 4.5 software The hurdle step was divided into 4 times instant ( $T 1$ : is referred to the instant of touchdown of the take off leg in front of the hurdle, T2: the take off, T3: flight phase and T4: landing phase. The selected 
kinematic parameters presented in Figure 1, table 1 were subjected to the analysis. Among the parameters there were 9 distance parameters, 10 angular parameters, 2 temporal parameters and 5 velocity parameters. Description of those parameters is shown in Table 1(adapted from Krzeszowski et al. 2014

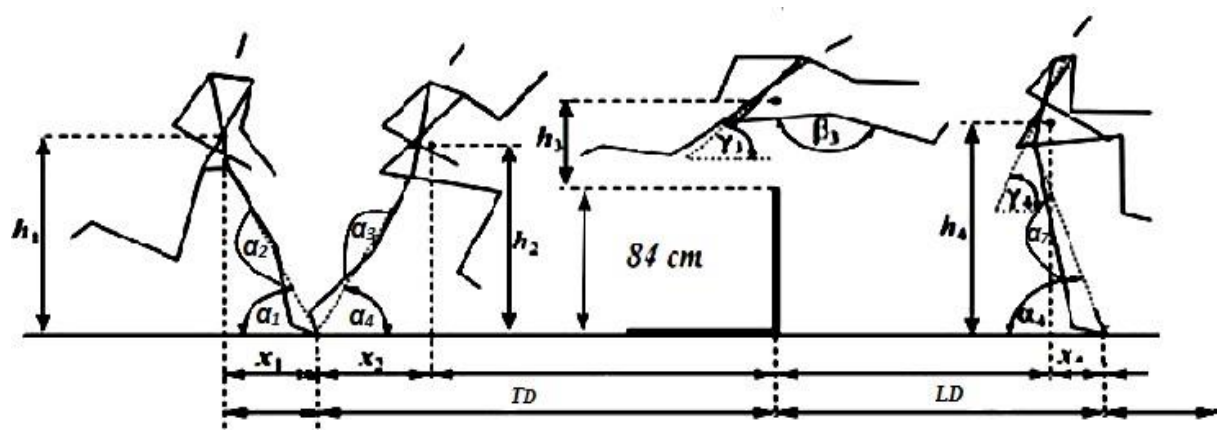

Figure 1: selected kinematic parameters of hurdle step (adapted from Krzeszowski et al. 2014)

T1 Touchdown of the takeoff leg h1 - height of center of gravity at touchdown

a1 - landing angle of the takeoff leg at touchdown

x1 - horizontal distance between CG and the foot at touchdown a2- trail leg Knee angle at touch down

a3 -trail leg Knee angle at maximum amortization

T3 Flight phase h3 - height of center of gravity over the hurdle

Y3 - trunk angle (attack)

$\beta 3$ - lead leg bending angle

T2- flight time
T2 : Takeoff phase

h2-height of center of gravity at takeoff

a4 - knee angle of trail leg at takeoff

a5 - takeoff angle

x2-horizontal distance between CG and the foot

T1- takeoff time

TD - takeoff distance to the hurdle

T4 Landing phase

h4 - height of center of gravity at touch down

a6 - landing angle of the lead leg

x4 - horizontal distance between CG and the foot

Y4 - trunk angle (touchdown)

a7- knee angle of lead leg at touchdown

LD - landing distance to the hurdle 


\section{Results:}

Based on the results of the kinematic analysis of the technique of clearing the 4th and 5th hurdle (during maximum velocity phase) the following findings can be summarized:

Table 2: Kinematic parameters of touchdown phase

$\begin{array}{cccc} & \text { Unit } & \begin{array}{c}\text { Fourth } \\ \text { hurdle }\end{array} & \text { Fifth hurdle } \\ \text { h1 } & \mathrm{m} & 0.76 & 0.76 \\ \mathbf{\alpha 1} & \circ & 60.0 & 65.0 \\ \mathbf{x 1} & \mathrm{m} & 0.33 & 0.32 \\ \mathbf{\alpha 2} & \circ & 157 & 158 \\ \mathbf{\alpha 3} & \circ & 145 & 147\end{array}$

Table 3: Kinematic parameters of takeoff phase

$\begin{array}{cccc} & \text { unit } & \begin{array}{c}\text { Fourth } \\ \text { hurdle }\end{array} & \text { Fifth hurdle } \\ \text { h2 } & \mathrm{m} & 0.81 & 0.83 \\ \mathbf{\alpha 4} & \circ & 173 & 170 \\ \mathbf{\alpha 5} & \circ & 71.0 & 67.0 \\ \mathbf{x 2} & \mathrm{m} & 0.33 & 0.32 \\ \text { T1 } & \text { sec } & 0.13 & 0.13 \\ \text { TD } & \mathrm{m} & 1.88 & 1.90\end{array}$

Table 4: Kinematic parameters of flight phase

$\begin{array}{cccc} & \text { unit } & \begin{array}{c}\text { Fourth } \\ \text { hurdle }\end{array} & \text { Fifth hurdle } \\ \text { h3 } & \mathrm{m} & 0.27 & 0.25 \\ \text { Y3 } & \circ & 56.0 & 55.0 \\ \boldsymbol{\beta} 3 & \circ & 153 & 153 \\ \text { T2 } & \text { sec } & 0.33 & 0.33\end{array}$




\section{International Journal of Sports Science and Arts}

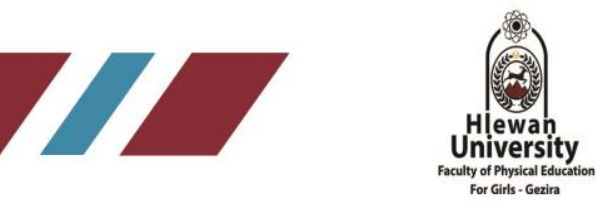

Table 5: Kinematic parameters of landing phase

$\begin{array}{cccc} & \text { unit } & \begin{array}{c}\text { Fourth } \\ \text { hurdle }\end{array} & \text { Fifth hurdle } \\ \text { h4 } & \mathrm{m} & 0.96 & 0.96 \\ \mathbf{\alpha 6} & \circ & 71.0 & 70.0 \\ \mathbf{X} 4 & \mathrm{~m} & 0.30 & 0.33 \\ \text { Y4 } & \circ & 72.0 & 69.0 \\ \mathbf{\alpha} 7 & \circ & 160 & 170 \\ \text { LD } & \mathrm{m} & 0.91 & 0.89\end{array}$

Table 6: CG horizontal velocities during hurdle step

\begin{tabular}{lccc} 
& unit & $\begin{array}{c}\text { Fourth } \\
\text { hurdle }\end{array}$ & $\begin{array}{c}\text { Fifth } \\
\text { hurdle }\end{array}$ \\
$\begin{array}{llcc}\text { CG velocity at the touch down in front } \\
\text { of the hurdle }\end{array}$ & $\mathrm{m} / \mathrm{s}$ & 7.20 & 7.25 \\
$\begin{array}{l}\text { CG velocity at the moment of takeoff } \\
\text { CG velocity during flight phase }\end{array}$ & $\mathrm{m} / \mathrm{s}$ & 6.6 & 6.6 \\
$\begin{array}{l}\text { CG velocity at the moment of } \\
\text { touchdown behind the hurdle }\end{array}$ & $\mathrm{m} / \mathrm{s}$ & 6.30 & 6.15 \\
$\begin{array}{l}\text { Average cm velocity during hurdle } \\
\text { step }\end{array}$ & $\mathrm{m} / \mathrm{s}$ & 6.00 & 6.20 \\
\hline
\end{tabular}

\section{Discussion:}

The main purpose of the present study is to identify the main kinematic variables during the clearance of $4^{\text {th }}$ and $5^{\text {th }}$ hurdle for national champion of $100 \mathrm{~m}$ hurdles and compare it with kinematic variables of elite level athletes .table 2 shows the values of kinematic variables of the touchdown phase for both $4^{\text {th }}$ and $5^{\text {th }}$ hurdle, during the touchdown of the takeoff leg in front of the $4^{\text {th }}$ and $5^{\text {th }}$ hurdle CG height was $0.76 \mathrm{~m}$ and it increases during the takeoff phase about 5 $\mathrm{cm}$ during the takeoff of the $4^{\text {th }}$ hurdle and about $7 \mathrm{~cm}$ during the takeoff of the $5^{\text {th }}$ hurdle .the increase of CG height between touchdown and takeoff of the trail leg is related to the change in trail 


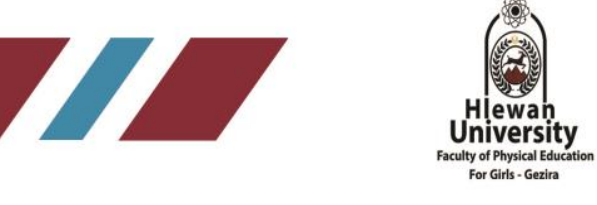

knee angle during the same phase which is needed to attacking the hurdle and lift the CG with maximum extension in knee joint at the moment of takeoff .the knee angle of the takeoff leg at touchdown in front of the hurdle was $157^{\circ}$ and $158^{\circ}$ for the $4^{\text {th }}$ and $5^{\text {th }}$ hurdle respectively and it increases at the takeoff to $173^{\circ}$ and $170^{\circ}$ for the $4^{\text {th }}$ and $5^{\text {th }}$ hurdle respectively the large decrease of the knee angle of the trail leg during the transition from touchdown to takeoff $\left(157^{\circ}\right.$ to $145^{\circ}$ in fourth hurdle and $158^{\circ}$ to $147^{\circ}$ in fifth hurdle ) may reflects both poor preparation to takeoff phase that the foot lands far from the CG,and low utilization of elastic power of leg muscles. Milan Coh and Ales Dolonec (1996) suggested that a minimum Flexion at the knee of the take-off leg must be very slight, which results in a minimal loss of horizontal velocity before hurdle clearance.[11]

During touchdown of the trail leg in front of the hurdle, the landing angle of the takeoff leg was $60^{\circ}$ and $65^{\circ}$ for the $4^{\text {th }}$ and $5^{\text {th }}$ hurdle respectively those values were less than the values of elite level female hurdlers during the same phase $\left(68^{\circ}-67^{\circ}\right.$ respectively) also, the horizontal distance between CG and the point of touchdown behind the hurdle was $0.33 \mathrm{~m}$ and $0.32 \mathrm{~m}$ for the $4^{\text {th }}$ and $5^{\text {th }}$ hurdle respectively however those values were larger than the values reported for elite female hurdlers which obtained during the same phase (0.29 $\mathrm{m}-0.29 \mathrm{~m}$ respectively) that may explain the large landing angle of the takeoff leg the subject places the takeoff foot far from the CG which causes an increase in the takeoff time $(0.13 \mathrm{sec})$ and decrease of horizontal velocity at the moment of takeoff (table 6), Milan Coh and Ales Dolonec (1996) suggested that the effectiveness 
of the hurdle clearance depends on the good preparation of takeoff phase during the last step before takeoff The hurdler must places the take- off foot actively below the CG so that would decrease the landing distance of takeoff step and decrease the loss of horizontal velocity at the moment of takeoff [11] .

The take-off in front of the hurdle is one of the elements of vital importance to optimal hurdle clearance, since it directly affects and defines the trajectory of the movement of CG over the hurdle and depends on the angle of takeoff [5] Table 2 shows the takeoff angle during the $4^{\text {th }}$ and $5^{\text {th }}$ hurdle, the takeoff angle was $71^{\circ}-67^{\circ}$ for the $4^{\text {th }}$ and $5^{\text {th }}$ hurdle respectively, those values were less than the values of elite female hurdlers at the same moment $\left(76^{\circ}-74^{\circ}\right.$ respectively)[11] that may explain the low CG height over the hurdle of the research subject $(0.27 \mathrm{~m}-0.25 \mathrm{~m})$ compared with elite female hurdlers $(0.36 \mathrm{~m}-0.46 \mathrm{~m})$ which presents an advantage for the national champion during clearing the hurdles that may helps her during the transition from hurdle step to sprinting between hurdles , (McFarlane, 2001) suggested that the main factor that affect the transition from hurdle step to sprinting between hurdles is to maintain a closer CG to the natural sprinting path during hurdle clearance, so the hurdler will be able to recover during the landing and recovery step phase $[10,15]$

The efficient of hurdle clearance depends on the optimal combination between many factors such as takeoff angle, takeoff distance and the active placing of the takeoff foot on the ground[4,5] table 4 shows that trunk incline angle was $56^{\circ}-55^{\circ}$ for both $4^{\text {th }}$ and 


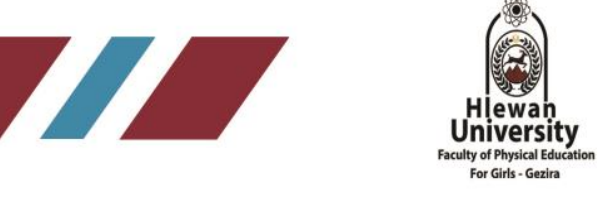

$5^{\text {th }}$ hurdle respectively which means that the subject tends to push the shoulders aggressively towards the hurdle early during the takeoff phase, also, the lead leg knee angle was $153^{\circ}$ for the $4^{\text {th }}$ and $5^{\text {th }}$ hurdle (Johannes Hucklekemkes 1990) suggested that the straightening of the lead leg should not be stressed during flight phase which would help the hurdler to reach the optimal position during landing and the transition to normal sprinting position [8]also, the knee bent of the lead leg during hurdle clearance plays an important role in decreasing flight time over the hurdle to get back to the ground as fast as possible For efficient hurdle clearance, the point of the take-off and the point of landing after hurdleclearance are very important. Because the correct position of these two points is a prerequisite for an optimal CG flight trajectory during flight phase and affects both trajectory and flight time of CG,( Johannes Hucklekemkes 1990) reported that the optimal takeoff distance to the hurdle for female hurdlers is about $1.90 \mathrm{~m}$ to $2 \mathrm{~m}$ to the hurdle[8], in the present study the takeoff distance was $1.88 m-1.90 m$ for the 4 and 5 hurdle respectively those values are less than the values of elite female hurdlers which was $2.16 m-2.09$ for the $4^{\text {th }}$ and $5^{\text {th }}$ hurdle respectively [11] however the landing distance for the research subject was $0.91 \mathrm{~m}-0.89 \mathrm{~m}$ for $4^{\text {th }}$ and $5^{\text {th }}$ hurdle respectively those results also are less than the same elite hurdler which the landing distance at the same position was $1.13 \mathrm{~m}--$ $1.00 \mathrm{~m}$ respectively. Although the research subject has less hurdle step length $2.79 \mathrm{~m}$ compared with the elite female hurdler $(3.29 \mathrm{~m})[4,11]$ the hurdle step time for the elite female hurdler was less than the research subject $(0.30 \mathrm{sec}$ compared to the research subject 


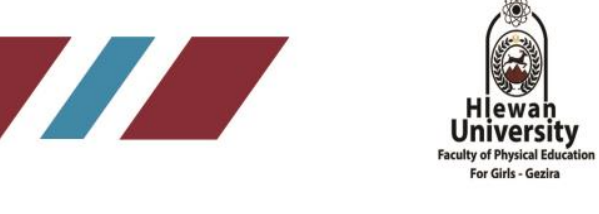

$0.33 \mathrm{sec}$ )that may due to the differences of both physical and morphological characteristics between the elite and sub-elite female hurdlers (Milan Coh et al 2000 )suggested that both takeoff and landing distance is an individual trait and is related to the morphological characteristics of the hurdler and with the take- off angle[13]. In addition to that, the correct position, the kinematicdynamic structure of take-off and landing, which directly affects the velocity of hurdle clearance and affects the efficiency of the transition from sprinting to hurdles and vice versa.

Table 5 shows the kinematics of landing phase of the research subject, the height of CG at touchdown was $0.96 \mathrm{~m}$ for the $4^{\text {th }}$ and $5^{\text {th }}$ hurdle $(\mathrm{CG} /$ body height $=0.69)$, also, the trunk incline angel at the moment of touchdown was $72^{\circ}-69^{\circ}$ respectively which ensures optimal conditions for an efficient rhythm of strides between the hurdles and maintenance of speed. The position of the CG at the moment of touch- down after the clearance of the $4^{\text {th }}$ and $5^{\text {th }}$ hurdle facilitates a very smooth transition to the sprint between the hurdles.

The knee angle of the lead leg at touch down behind the hurdle was $160^{\circ}-170^{\circ}$ for the $4^{\text {th }}$ and $5^{\text {th }}$ hurdle respectively which explain the relative height of $\mathrm{CG}$ at touchdown, Johannes Hucklekemkes 1990 suggested that a more extended lead leg knee angle after clearing the hurdle is necessary to maintain a high CG position which helps the athlete to get back to normal sprinting conditions after clearing the hurdle with a minimum loss of horizontalvelocity [8] 
The landing angle of the lead leg behind thehurdle was $71^{\circ}$ $70^{\circ}$ for the $4^{\text {th }}$ and $5^{\text {th }}$ hurdle respectively, also the horizontal distance from CG to the foot at the instant of touchdown was $0.30 \mathrm{~m}$ $-0.31 \mathrm{~m}$ respectively. Those values was similar to the values of elite female hurdler that the landing angle was 68 but the horizontal distance of CG to the foot at touchdown was 0.29 which means that the elite athlete places the foot of the lead leg down the CG to decrease contact time and maintain the horizontal velocity of $C G$ after hurdle clearance. Milan coh et al 2000 suggested that the landing phase, is one of the key elements of hurdle clearance technique, so the athlete must places the foot of the lead leg behind CG to decrease both contact time and the braking phase in order to maintain the horizontalvelocity of the CG while clearing the hurdle.[11,12,13]

Table 5 shows values of CG velocities during different instants of hurdle step,CG horizontal velocity of the subject at the moment of touchdown in front of the hurdle was $7.20 \mathrm{~m} / \mathrm{s}-7.25 \mathrm{~m} / \mathrm{s}$ for the $4^{\text {th }}$ and $5^{\text {th }}$ hurdle respectively, then, CG horizontal velocity decreased about $8.3 \%-8.9 \%$ during the instant of takeoff respectively, those values were different for the values reported for elite female hurdlers $8.29 \mathrm{~m} / \mathrm{s}-8.40 \mathrm{~m} / \mathrm{s}$ and the loss of horizontal velocity was $5.8 \%$.the percentage of loss in horizontal velocity during the transition to takeoff position was larger than values reported for elite female hurdler (8.3\% - $8.9 \%$ comparedto $5.8 \%$ for elite female hurdlers)[11], CG velocity during takeoff depends on many factors such as CG velocity during sprinting between hurdles, minimizing braking phase 


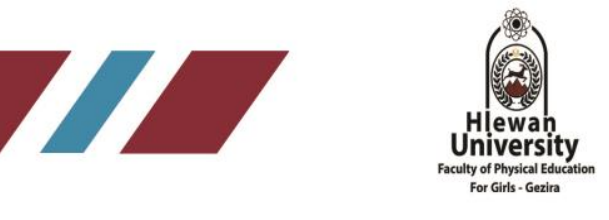

and landing distance at takeoff step, Also, the optimum execution of hurdle step depends on the aggressive shorting of the last step by placement of takeoff foot as fast as possible under the CG to avoid the loss of horizontal velocity during takeoff[4] that may explain the large loss in horizontal velocity of CG during takeoff that the research subject places the foot of the takeoff leg far from CG $(0.32 \mathrm{~m}$ compared with elite female hurdler $0.29 \mathrm{~m}$ ),During the transition from hurdle clearance to landing, the loss of CG horizontal velocity was $4.5 \%$ $2.8 \%$ during flight and landing after hurdle clearance respectively, the research subject has a good execution of hurdle clearance with a minimum loss of CG horizontal velocity due to the decrease of $C G$ height over the hurdle $(0.25)$ and an optimal landing angle $\left(71^{\circ}-70^{\circ}\right)$ that helps her to reach the optimal position to sprinting between hurdles.

\section{Conclusion:}

Many of the differences in hurdle clearance technique between elite hurdle and sub-elite female hurdlers analyzed in the present study are fairly small as indicated by the present data such as horizontal distance between CG and foot at the moment of takeoff ,takeoff and landing distance,. However, hurdle clearance velocity is a key role differentiating the race performance among elite female hurdlers This can ensure the importance of achieving high horizontal velocitybetween the hurdles and maintaining it during the hurdle clearance, also maintaining a relative high CG height during touchdown after hurdle clearance has a major role in maintaining horizontal velocity after clearing the hurdle and fast transition to 


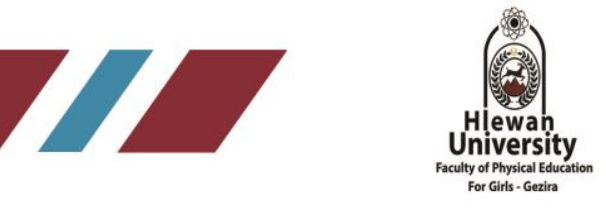

normal sprinting technique between hurdles this can be achieved by designing efficient drills to minimize takeoff distance of takeoff step and efficient elastic strength training which will result in low takeoff time and low relative knee flexion during takeoff.

\section{References}

1 Amritpal : Relationship Among the Technique of Hurdle Singh Sidhu, Clearance Over the Different Hurdles in 110m Shamsher Race International Journal of Science and $\begin{array}{ll}\text { Singh Jang } & \text { Research (IJSR) ISSN (Online): 2319-7064 }\end{array}$

2 Brian McLean : The biomechanics of hurdling: Force plate analysis to assess hurdling technique 9:4; 55-58. 1994

3 González : Navarro 60 METERS HURDLES STEP FrutosP,Mallo, LENGTH ANALYSIS ATDIFFERENT Veiga, COMPETITIVE LEVELS

4 Helmar : IOOm hurdles: Gail Devers NSA Hommel photosequence 11:1:71-75. 1996

5 Janusz Iskra : The most effective technical training for the 110 metres hurdles 10:3:51-55,1995

6 Janusz Iskra : A REVIEW OF BIOMECHANICAL STUDIES Milan Čoh IN HURDLE RACES Kinesiologia Slovenica, 12, 1, 84-102 (2006)

7 Jason Francis, : KINEMATIC ALTERATIONS IN WOMEN'S Alfred Finch, 100M HURDLETECHNIQUE OVER andGideon Ariel CURRENT 84CM HURDLE AND PROPOSED 91CM HURDLE HEIGHTS Isas 2004/ Ottawa, Canada

8 Johannes : Model technique analvsis sheets for the Hucklekemkes hurdles RAR'r VI: Thc Women's 100 metres 
Hurdles I 33-58 1990£>byl.A,A,F.

9 Krzysztof : AN ATTEMPT TO ASSESS THE SELECTED PRZEDNOWE HURDLE STEPKINEMATIC PARAMETERS K(

Bartosz DZIADEK, Stanisław USING METHODS OF COMPUTER VISION CIESZKOWSKI Scientific Review of Physical Culture, volume 5 , issue 4

,

Artur

STOPYRA

10 Laurence R. : A Biomechanical Analysis of Male and Bollschweiler Female Intermediate Hurdlers and Steeplechasers Brigham Young University Provo Brigham Young University BYU ScholarsArchive All Theses and Dissertations 2007-12-19 30

11 Milan Coh : Three-dimensional kinematic analysis ofthe and Ales Dolonec hurdles technique used byBrigita Bukovec11:1:63-69, 1996

12 Milan Coh : Biomechanical analysis of Colin Jackson's hurdle clearance technique 18:1;37-45 2003

13 Milan Coh, : KINEMATIC AND DYNAMIC ANALYSIS OF BojanJošt, HURDLE CLEARANCETECHNIQUE Branko Škof,

14 Sami Kuitunen: KINEMATIC ANALYSIS OF HURDLE andStephen CLEARANCE OF 60-M HURDLES IN ELITE Poon HURDLE SPRINTERS DURING WORLD INDOORCHAMPIONSHIPS 2010 
Sang-Kyoon SPRINTING CHARACTERISTICS OF

15 Park Sukhoon : WOMEN'S 100 METER FINALSAT THE Yoon and Jiseon Ryu Won- Seob Hwang Joo-Nyeon IAAF WORLD CHAMPIONSHOPS DAEGU 2011 Sang-Kyoon Park. Sprinting characteristics of women's 100 meter finals Kim Sunghe Ha Hiroyuki

Koyama

Takashi

Mochida

Zhong $\mathbf{X u}$, KINEMATICAL RESEARCHON HURDLE

16 Jing Wang, : CLEARANCE TECHNIQUES ISBS Jingshan Li, Conference 2008, July 14-18, 2008, Seoul, Xiaofeng Li, and Jihe Zhou Korea 582 